\title{
The Lou Massa Issue: Congratulations and Thanks
}

\section{Istvan Hargittai ${ }^{1}$}

Published online: 31 July 2017

(C) Springer Science+Business Media, LLC 2017

This issue is devoted in its entirety to celebrating Professor Lou Massa on the occasion of his 75th birthday. All papers in this issue in one way or another represent a reflection of Lou's interest. In addition, five more articles presented in the previous issue of Structural Chemistry are components of this compilation. They are listed here and together with these five papers the collection dedicated to Lou is complete. Congratulations, Lou, and Many Happy Returns!

\section{A 3D structural model of RsXXVIA, an $\omega$-conotoxin}

By Sergio A. Román-González, Edson Edinho RoblesGómez, Jorge Reyes, Johanna Bernáldez, Fernando CortésGuzmán, Karina Martínez-Mayorga, Fernando LazcanoPérez, Alexei Licea, Roberto Arreguín-Espinosa [1]

How strong are H-bonds at the fully hydroxylated silica surfaces? Insights from the B3LYP electron density topological analysis

By Federico Musso, Silvia Casassa, Marta Corno, Piero Ugliengo [2]

Insights from domain-averaged Fermi hole (DAFH) analysis and multicenter bond indices into the nature of $\mathrm{Be}(0)$ bonding By Robert Ponec, David L. Cooper [3]
Triel bonds-complexes of boron and aluminum trihalides and trihydrides with benzene

By Sławomir J. Grabowski [4]

A computational investigation into the redox chemistry of Mo-and W-tris(diselenolene) complexes

By Eric A. C. Bushnell, Matt R. Adams, Russell J. Boyd [5]

The occasion of publishing this thematic issue is also a celebration for our journal for the high scientific level of these contributions. Professor Chérif F. Matta guest edited this issue with dedication and high professional standards. I express my heartfelt thanks to Chérif for bringing together this rich collection of papers.

\section{References}

1. Román-González SA, Robles-Gómez EE, Reyes J, Bernáldez J, Cortés-Guzmán F, Martínez-Mayorga K, Lazcano-Pérez F, Licea A, Arreguín-Espinosa R (2017) Struct Chem 28:901-909

2. Musso F, Casassa S, Corno M, Ugliengo P (2017) Struct Chem 28: 1009-1015

3. Ponec R, Cooper DR (2017) Struct Chem 28:1033-1043

4. Grabowski SJ (2017) Struct Chem 28:1163-1171

5. Bushnell EAC, Adams MR, Boyd RJ (2017) Struct Chem 28:11731180

Istvan Hargittai

stuceditor@gmail.com

1 Department of Inorganic and Analytical Chemistry, Budapest

University of Technology and Economics, PO Box 91,

Budapest 1521, Hungary 